Revista Educação e Políticas em Debate - v. 7, n. 1, p. 152- 169 - jan./abr. 2018 - ISSN 2238-8346

\title{
Escolas multisseriadas do campo: tempos, espaços e vivências
}

\author{
Multiseriate schools of the field: legitimation of a historical trajectory \\ Écoles multi-sérialisé du champ: temps, espaces et expériences
}

\author{
Edirleine dos Santos Pereira ${ }^{1}$ \\ Universidade Estadual de Montes Claros \\ Magda Martins Macêdo ${ }^{2}$ \\ Universidade Estadual de Montes Claros
}

\begin{abstract}
Resumo: Este texto discute a relevância social, política e cultural das escolas multisseriadas do campo, a partir das memórias e vivências de sujeitos que ali trabalharam e estudaram, considerando os princípios da Educação do Campo. Foi realizada uma pesquisa explicativa, referenciada no Paradigma Interpretativo e na tipologia História Oral, com sujeitos oriundos de escolas multisseriadas do Campo, enfatizando suas memórias e percepções sobre esse espaço de ensino, de aprendizagem e de vida. Fundamentou-se nos trabalhos de Antunes-Rocha e Hage (2010), Santos e Moura (2010) e Hage (2008; 2014). Ressalta-se nessa experiência brasileira de escola do Campo, existe um trabalho pedagógico que atende e enriquece a história da educação ao valorizar a diversidade, assim como exerce uma função social nas comunidades como materialização do direito à Educação do Campo, não se justificando o seu fechamento.
\end{abstract}

Palavras-chave: Educação do Campo. Escolas Multisseriadas do Campo. Vivências.

Abstract: This research aims to analyze the historical trajectory of the Multiseriate Schools of the Field, in the perspective of its legitimation. It was carried out an explanatory research, referenced in the Interpretative Paradigm and in the Oral History typology, with subjects coming from Multiseriate Schools of the Field, emphasizing their memories and representations. As bibliographies was based on the works of Antunes-Rocha and Hage (2010), Santos and Moura (2010) and Hage (2008; 2014). Finally, it was questioned that there is a pedagogical work in this Brazilian country school experience that serves and enriches the history of education by valuing diversity, as well as exercising a social function within the communities while materializing the right to education in the countryside, and its closure is not justified.

Key words: Field Education. Multisite Schools in the Field. Experiences.

Résumé: Ce texte discute la pertinence sociale, politique et culturelle des écoles rurales multigrades, en se basant sur les souvenirs et les expériences des sujets qui y ont travaillé et étudié, en considérant des principes du programme "Educação do Campo" (l'Education en

1 Pedagoga pela Universidade Estadual de Montes Claros - Unimontes. E-mail:santos.edileny@hotmail.com.

2 Professora do Departamento de Educação/Unimontes. Coordenadora do Laboratório de Educação do Campo no Semiárido Mineiro: Identidade, Território, Agroecologia - LABédoCAMPO. Membro da Articulação Mineira de Educação do Campo e da Rede de Educação do Semiárido Brasileiro - RESAB. E-mail: magdamartinsm@yahoo.com.br 
Revista Educação e Políticas em Debate - v. 7, n. 1, p. 152- 169 - jan./abr. 2018 - ISSN 2238-8346

milieu rural). Une recherche explicative a été réalisée, référencée dans le Paradigme Interprétatif et dans la typologie de l'Histoire Orale, avec des sujets provenant d'écoles multigrades des zones rurales, mettant l'accent sur leurs souvenirs et leurs perceptions de cet espace d'enseignement, d'apprentissage et de vie. La recherche est fondée sur les travaux d'Antunes-Rocha et Hage (2010), Santos et Moura (2010) et Hage (2008, 2014). Il faut souligner dans cette expérience brésilienne de l'école en milieu rural, qu'il existe un travail pédagogique qui répond et enrichit l'histoire de l'éducation en valorisant la diversité et en exerçant une fonction sociale dans les communautés en tant que matérialisation du droit à l'Education en milieu rural, ne justifiant pas sa fermeture.

Mots-clés: Education en milieu rural. Écoles multigrades en milieu rural. Expériences.

Recebido em: 05 de julho de 2018

Aceito em: 10 de outubro de 2018

\section{Introdução}

Este artigo tem como objetivo central discutir os desafios postos ao reconhecimento da trajetória das escolas multisseriadas do Campo e as possibilidades para a sua afirmação como um dos modelos de escola camponesa, sublinhando a relevância social, política e cultural dessas escolas, a partir das memórias e vivências de sujeitos que ali trabalharam e estudaram, considerando os princípios da Educação do Campo.

Grande parte das escolas multisseriadas do Campo localiza-se em pequenas comunidades afastadas das sedes dos municípios, onde diversos fatores incidem diretamente no exercício docente. Tais escolas, além de enfrentar adversidades relacionadas às condições de funcionamento, lidam com a visão estereotipada de que a heterogeneidade encontrada na multisseriação é um obstáculo à educação classificada como "de qualidade”. Isso faz com que a aprendizagem nas escolas multisseriadas do Campo seja avaliada como inferior, acarretando a desvalorização dos seus profissionais e estudantes, assim como de todos os povos do Campo. Tal concepção negativa, historicamente construída, foi incorporada pela sociedade e, particularmente, pelos próprios professores e estudantes pertencentes a essa realidade.

Sob essa linha de pensamento, este estudo partiu da seguinte inquietação: quais os desafios para o reconhecimento da trajetória das escolas multisseriadas do Campo e as possibilidades para a sua afirmação como um dos modelos de escola camponesa? Buscando responder a tal questionamento, foi realizado um estudo alicerçado no Paradigma Interpretativo que tem como interesse central o significado da vida social e o seu esclarecimento pelo pesquisador. Ressalta-se que este pesquisador não é neutro e, na medida 
Revista Educação e Políticas em Debate - v. 7, n. 1, p. 152- 169 - jan./abr. 2018 - ISSN 2238-8346 em que interpreta e articula as experiências em relação ao mundo, ele conhece a realidade social por meio do seu entendimento subjetivo (MOREIRA; CALEFFE, 2006). Trata-se de um estudo explicativo que tem por intuito compreender as causas do fenômeno pesquisado.

Iniciou-se com uma pesquisa bibliográfica acerca do tema, pois, de acordo com Gil (1991), esse procedimento permite conhecer um conjunto maior de fenômenos do que pesquisando diretamente. Nessa perspectiva, foi realizado um estudo acerca das escolas multisseriadas e do Movimento pela Educação do Campo, destacando-se como bibliografia principal os trabalhos organizados por Antunes-Rocha e Hage (2010), Santos e Moura (2010) e Hage (2008; 2014).

Posteriormente, partiu-se para a pesquisa de campo, na qual o levantamento das informações foi realizado a partir da tipologia História Oral, tendo em vista que o objetivo deste estudo está voltado para o reconhecimento de uma trajetória que é histórica e, portanto, demarcada social, política e culturalmente. Dito isso, foram priorizadas as percepções, lembranças e memórias dos sujeitos pesquisados com o objetivo de dar novo significado às experiências de outras épocas, vivenciadas em escolas multisseriadas, de modo a compreender os entremeios da inferiorização atribuída a essas escolas, assim como analisar as suas possibilidades de transgressão. Quanto aos percursos operacionais metodológicos, foram realizadas quatro entrevistas abordando a trajetória educativa e profissional dos sujeitos.

Foram ouvidas Rosely e Guiomar, ex-professoras que iniciaram suas carreiras docentes em escolas multisseriadas do campo. Rosely tem 52 anos, é casada, graduada em Normal Superior, Pedagogia e Gestão, e pós-graduada em Supervisão, Inspeção e Orientação. Tem 23 anos de experiência como professora de escolas multisseriadas do Campo, atualmente é diretora das Escolas do Campo, na Secretaria Municipal de Educação de Buritizeiro/MG. Guiomar, 54 anos, é casada, graduada em Pedagogia, Mestre em Educação e teve a sua primeira experiência como docente em uma escola multisseriada do Campo. Atualmente, é especialista da Educação Básica na Rede Estadual e docente no Curso de Pedagogia, da Universidade Estadual de Montes Claros (Unimontes), campus Pirapora/MG.

Foram entrevistados, também, Altair e $\mathrm{João}^{3}$, atualmente acadêmicos dos cursos de Licenciatura em Geografia e Pedagogia da Unimontes, Campus Pirapora, com origens em comunidades camponesas no Norte de Minas Gerais, que tiveram suas primeiras experiências escolares em uma escola multisseriada.

3 Adotamos um nome fictício a fim de preservar a identidade do entrevistado, ressaltando que as demais entrevistadas permitiram que fossem utilizados seus nomes reais. 
Revista Educação e Políticas em Debate - v. 7, n. 1, p. 152- 169 - jan./abr. 2018 - ISSN 2238-8346

\section{Escolas multisseriadas do campo: realidades históricas e legais}

A trajetória histórica da escola multisseriada tem início ainda no século XIX, no qual o próprio Estado, com vistas a uma grande inovação educacional pelo método de Ensino Mútuo $^{4}$, incentiva o ensino de pessoas de diferentes idades e níveis de aprendizagem ao mesmo tempo a ser utilizado nas escolas de primeiras letras (NEVES, 2000). Já em 1893, aproximadamente sete décadas à frente, e após a República, foram criados os Grupos Escolares, especialmente nas cidades, que se organizavam a partir da seriação por idade e nível de aprendizagem e, em geral, com as crianças separadas por sexo. Contudo, ressaltamos que nas vilas e povoados, bem como na zona rural de maneira geral, continuaram em funcionamento as chamadas “escolas isoladas”, multisseriadas (SANTOS; MOURA, 2010).

Aqui se torna relevante informar que foram construídos prédios escolares notadamente grandiosos, visando refletir o peso dado pela República à instrução, entretanto, o mesmo não pode ser observado nos prédios escolares localizados na zona rural. Este atendimento preferencial às escolas urbanas demarca o histórico de discriminação com a população camponesa (RAMALHO, 2008). Ferri (1994) complementa afirmando que, nesse momento histórico, a grande preocupação passa a ser com a migração para as cidades, ameaçando a organização econômica e social do país.

De acordo ainda com Santos e Moura (2010), outro importante momento no histórico das escolas multisseriadas deu-se a partir da década de 1970, com a progressiva municipalização do ensino, iniciando o desenvolvimento de políticas municipais de educação, dentre elas, a criação e/ou municipalização de novas escolas, da política de nucleação das escolas, a definição da seriação como modelo ideal e, consequentemente, do transporte dos estudantes. A nucleação escolar, sabe-se, consistiu (e ainda persiste) no argumento de melhor atendimento escolar a partir de uma estrutura física, tecnológica e pedagógica ampliada, centralizada em escolas núcleo, com um maior número de estudantes que são transportados de suas comunidades para essa escola, o que tornou possível a divisão por "séries", bem como a formação contínua dos educadores, o acesso a uma biblioteca, a práticas de esportes - e posteriormente o acesso à internet -, dentre outros benefícios, propagandeados naquele momento histórico. Nas palavras de Fonseca (2011, p. 43),

\footnotetext{
4. O Ensino Mútuo consistia num método de origem inglesa, organizado e divulgado por Andrew Bell e Joseph Lancaster, destinado à instrução elementar popular que buscava suprir a falta de professores para uma grande massa de analfabetos sem onerar o Estado.
} 
com a ascensão do Regime Militar, na década de 1960 nos anos de ditadura, mais especificamente de 1964 a 1984, o país apresenta uma abertura significativa ao capital estrangeiro. Nesse contexto, a USAID (Agência dos Estados Unidos para o Desenvolvimento Internacional) foi o principal instrumento do governo norte americano para exercer influência em outros países, inclusive na área educacional. Tal agência foi responsável pelo subsídio à implantação do processo de nucleação de escolas brasileiras, sendo a escola rural multisseriada impactada por esse acordo e se tornado a experiência piloto para esta implantação.

Nesse sentido, as escolas multisseriadas foram (e permanecem sendo ao longo do tempo) “[ [...] tratadas como estratégia emergencial, como uma espécie de ‘tapa buraco’ para solucionar os problemas das escolas isoladas, que não contam com quantidade de estudantes suficiente para divisão da turma em séries" (RODRIGUES, 2009, p.72). Por terem sido secundarizadas, grande parte das condições indispensáveis para que se tenha uma boa educação foram suprimidas. Em decorrência disso, passaram a predominar no Campo escolas sem infraestrutura, sem recursos, sem profissionais capacitados, obrigados a atuar em péssimas condições de trabalho.

Somente no ano de 1997 foi instaurado no Brasil o Programa Escola Ativa (PEA), elaborado com base no Programa Escuela Nueva, de origem colombiana, desenvolvido nos anos 1980 e expandido na década de 1990, a princípio no Nordeste, constituindo-se, internacionalmente, como um modelo de reforma educacional no meio rural para a melhoria da qualidade do ensino em classes multisseriadas e para a formação de professores. Mas este não foi eficiente para atender às demandas educacionais do Campo e sofreu fortes críticas (SANTOS; MOURA, 2010).

No ano de 2008, o PEA, que até então era desenvolvido pelo Fundo de Fortalecimento da Escola (FUNDESCOLA), passou a ser gerido pela Coordenação Geral de Educação do Campo (CGEC), trazendo à tona a necessidade de se reformular o Programa de modo a incluir os princípios e conceitos da Educação do Campo (GONÇALVES; ANTUNES-ROCHA; RIBEIRO, 2010). Essa reformulação proporcionou a ampliação do debate sobre a multisseriação, colocada como desafio de se refletir sobre a própria escola, suas séries, disciplinas, conteúdos e avaliações.

O Programa Escola Ativa propõe estratégias que estimulam a aprendizagem ativa e contextualizada, tendo o professor como mediador dos processos, a construção cooperativa do conhecimento, a gestão participativa na escola, a interação com a comunidade e a formação continuada dos educadores (GONÇALVES; ANTUNES-ROCHA; RIBEIRO, 2010). Contudo, 
Revista Educação e Políticas em Debate - v. 7, n. 1, p. 152- 169 - jan./abr. 2018 - ISSN 2238-8346

Gonçalves, Antunes-Rocha e Ribeiro (2010, p. 58-59) criticam a falta de produção coletiva na reformulação do PEA, guiada pelos modelos do MEC e não pela história das escolas e professores do Campo:

[...] o diálogo com a prática pedagógica historicamente construída pelos docentes, quem sabe, possa ser um caminho para flexionar os rumos do PEA. Partir da prática e não dos guias. Guiar-se pela experiência e não pela metodologia. Caminhar rumo à construção de uma escola comprometida com a formação de uma sociedade sustentável e não como ferramenta de promoção do desenvolvimento rural.

Nesta mesma linha de pensamento, Taffarel e Santos Júnior (2016, p. 437) assinalam que o "[...] desafio colocado a este programa é a sua coerência com a especificidade e as necessidades dos trabalhadores do campo, no sentido de alterar o trabalho pedagógico nas/das classes multisseriadas".

$\mathrm{Na}$ perspectiva de se apresentar como possibilidade para a escola multisseriada do Campo e visando fortalecer a escola como espaço de vivência social e cultural, foi instaurado, em 2013, o Programa Escola da Terra que “[ [...] deve constituir um espaço de movimento educativo, oportunizando a dialética dos saberes, a valoração dos saberes locais, pressupondo uma educação que contribua para a emancipação dos sujeitos” (JUSTINO, 2015, p.11).

Conforme o Manual de Adesão do Programa (BRASIL, 2013), esta ação tem como finalidades: promover a formação continuada específica de professores para que atendam às necessidades de funcionamento das escolas do Campo e das localizadas em comunidades quilombolas e oferecer recursos didáticos e pedagógicos que atendam às especificidades formativas das populações do Campo e Quilombolas.

Nada obstante, mesmo com esse Programa e a legislação atual que trata da Educação do Campo, grande parte dos problemas enfrentados no dia a dia das suas escolas continua sem ser resolvida, por conseguinte, escolas continuam sendo fechadas. E o Movimento de Educação do Campo, que se tece num contex to de busca pela mudança dessa situação, vem mobilizando sujeitos e instituições em prol das escolas multisseriadas, como modo de organização escolar empregada para garantir o direito à Educação do/no Campo.

No que tange aos dispositivos legais que contemplam as escolas multisseriadas, destaca-se a LDB n. ${ }^{\circ}$ 9.394 (BRASIL, 1996) que, em seu art. $3^{\circ}$, inciso I, estabelece como princípio “a igualdade de condições para o acesso e permanência na escola”, oferecendo argumento jurídico contra as políticas de fechamento dessas escolas. Além disso, no art. $23^{\circ}$ dessa Lei (BRASIL, 1996), amparando o modo de organização escolar multisseriado, institui- 
se que

a educação básica poderá organizar-se em séries anuais, períodos semestrais, ciclos, alternância regular de períodos de estudos, grupos não seriados, com base na idade, na competência e em outros critérios, ou por forma diversa de organização, sempre que o interesse do processo de aprendizagem assim o recomendar (grifos nosso).

Outro importante suporte legal, sobre as escolas multisséries, é a Resolução n. ${ }^{\circ} 1$ do Conselho Nacional de Educação (CNE) e Câmara de Educação Básica (CEB), que estabelece as Diretrizes Operacionais para a Educação Básica nas Escolas do Campo (BRASIL, 2002). No art. $7^{\circ}$, revalida a flexibilidade dos espaços pedagógicos e tempos de aprendizagem, respeitando sempre os princípios da política de igualdade.

Outrossim, as Diretrizes Complementares, definidas pela Resolução CNE/CEB n. ${ }^{\circ}$, de 28 de abril de 2008 (BRASIL, 2008), sublinham, em seu art. $3^{\circ}$, que "a Educação Infantil e os anos iniciais do Ensino Fundamental serão sempre oferecidos nas próprias comunidades rurais, evitando-se os processos de nucleação de escolas e de deslocamento das crianças", o que apresenta-se como aparato legal contra o avanço da nucleação de escolas do Campo.

Outro aspecto extremamente relevante assegurado por essa Resolução (BRASIL, 2008) é a definição de aspectos necessários ao funcionamento das escolas multisséries:

art. 10. $\S 2^{\circ}$. As escolas multisseriadas, para atingirem o padrão de qualidade definido em nível nacional, necessitam de professores com formação pedagógica, inicial e continuada, instalações físicas e equipamentos adequados, materiais didáticos apropriados e supervisão pedagógica permanente.

O ensino multisseriado no Campo é salvaguardado, também, pelo Decreto n. ${ }^{\circ}$ 7.352, de 4 de novembro de 2010 (BRASIL, 2010) que, em seu art. $7^{\circ}$, inciso I, prevê que os entes federados assegurarão a “[ [...] organização e funcionamento de turmas formadas por alunos de diferentes idades e graus de conhecimento de uma mesma etapa de ensino, especialmente nos anos iniciais do ensino fundamental”.

O Programa Nacional de Educação do Campo (PRONACAMPO), por meio da Portaria n. ${ }^{\circ} 86$, de $1^{\circ}$ de fevereiro de 2013 (BRASIL, 2013), abarca, também, ações voltadas para as escolas multisseriadas. No seu eixo n. ${ }^{\circ}$ 1, destaca-se a "Escola da Terra" que " $[\ldots]$ busca promover o acesso, a permanência e a melhoria das condições de aprendizagem dos estudantes do Campo e quilombolas em suas comunidades" (BRASIL, 2013, p.3).

Analisando os marcos legais, fica claro que a flexibilidade nos processos de ensino e de 
Revista Educação e Políticas em Debate - v. 7, n. 1, p. 152- 169 - jan./abr. 2018 - ISSN 2238-8346 aprendizagem apresenta-se como um dos principais eixos da Educação do Campo, evidenciando que, quanto aos tempos e espaços, não existe uma única forma de organização escolar capaz de responder às demandas educacionais. Dito de outro modo, os pressupostos da educação camponesa defendem que, ao invés de sobrepor determinado paradigma, é preciso conhecer e compreender o contexto em que esses processos acontecem para elaborar e executar um projeto educativo próprio para cada realidade, a fim de se democratizar a educação. E a escola multissérie faz parte da realidade do Campo brasileiro.

O Censo Escolar de 2009 (ANTUNES-ROCHA; HAGE, 2010) indica a existência de 96,6 mil turmas multisseriadas no Brasil, lembrando que o uso do termo "multisseriada” advém de um legado urbano pautado na organização escolar "seriada". E perscrutando a realidade das escolas multisseriadas do Campo, fica claro que o modo de organizar o processo educativo não é o principal dificultador do trabalho docente. Observam-se problemas pertencentes à infraestrutura, às condições de trabalho para os professores, entre outros.

Os dados do Censo Escolar de 2011 (ANTUNES-ROCHA; HAGE, 2010) retratam essa situação desfavorável ao indicar que 90,1\% das escolas multisseriadas não têm internet acessível, 15\% não dispõem de energia elétrica, 10,4\% não possuem água potável e 14,7\% não possuem esgoto sanitário. Além da falta de infraestrutura e de recursos pedagógicos, o educador enfrenta dificuldades, também, em relação às suas condições de trabalho. Gonçalves, Antunes-Rocha e Ribeiro (2010, p.49), ressaltam que

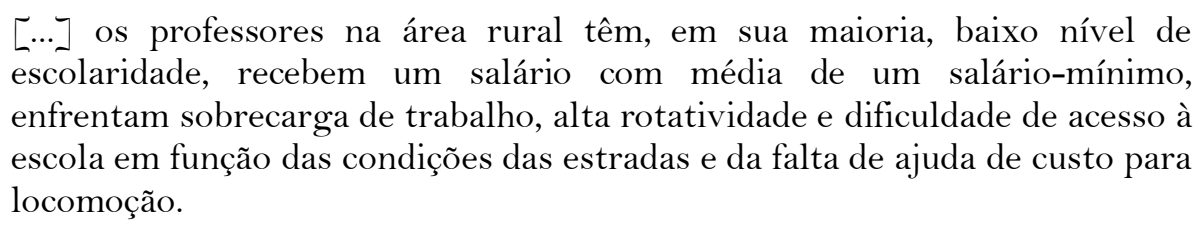

Essas e outras dificuldades acabam por desmotivar os professores a buscarem essas escolas como local de trabalho, e os que nela estão não querem permanecer. Embora esse modelo de organização escolar represente a principal característica da maioria das escolas camponesas, a escola multisseriada ainda se encontra concatenada ao descaso, à secundarização e ao preconceito que elege a multisseriação como responsável pelo fracasso escolar no campo. Tais problemas têm referenciado essas escolas com a precariedade da educação ofertada no Campo.

Além disso, com a racionalização do trabalho docente, traço da estrutura burocrática urbana, produto da municipalização do ensino, há um enrijecimento da prática diária que impede o educador de planejar e desenvolver suas aulas com autonomia e flexibilidade, 
Revista Educação e Políticas em Debate - v. 7, n. 1, p. 152- 169 - jan./abr. 2018 - ISSN 2238-8346 respeitando os ritmos e tempos de aprendizagem dos estudantes, seus saberes e sua cultura. De acordo com Antunes-Rocha e Hage (2010), na multissérie, tentando reproduzir o modelo das escolas urbanas, os professores adotam estratégias próprias para dialogar com a "série" reinventam os espaços com a divisão das séries por filas de carteiras, separando o quadro, contando com o apoio dos estudantes mais adiantados - muitas vezes de forma intuitiva devido à falta de apoio pedagógico.

Não obstante, as escolas do campo multisseriadas continuam sendo fechadas. Os dados do Censo Escolar INEP/MEC apontam mais de 31\% de escolas fechadas. Dentre as justificativas utilizadas para essa agressão aos povos camponeses está a redução dos gastos por meio da nucleação das escolas consideradas de pequeno porte e a melhoria no ensino e na aprendizagem - descredenciando o ensino multisseriado. Todavia, tais premissas não se sustentam, na medida em que transferir os estudantes para escolas de "grande porte", de modo que possam ser separados por ano escolar, por si só não garante a elevação na qualidade da educação, bem como há uma discrepância quanto à redução de gastos ao passo que com a nucleação elevam-se, substancialmente, os valores dispensados ao transporte escolar.

Conforme as investigações que vem sendo realizadas a respeito desse fenômeno, em especial após a difusão do Movimento da Educação do Campo, as ações que norteiam o fechamento das escolas no Campo estão diretamente ligadas à lógica economicista do agronegócio que visa a uma verdadeira mercantilização do campo. Dessa forma, a adoção da política de fechamento de escolas do campo, como alternativa mais econômica amparada pelo discurso da racionalização da rede escolar, tem reduzido a questão a um simples problema de sistema escolar, na medida em que omite seu aspecto social mais geral e complexo relacionado à perversa expansão do capitalismo no campo e suas consequências para os seus trabalhadores. Os fatores que ocasionam o fechamento das escolas provêm de condicionantes externos a própria escola (MAZUR, 2015).

Vendramini (2015) compartilha de tal ideia ao afirmar que o futuro das escolas se encontra diretamente ligado ao futuro do Campo, um espaço em processo de urbanização e mudanças que implicam a saída de grande parte da população que nele vive. Taffarel e Munarin (2015) acrescentam que, com o fechamento de escolas, extingue-se a possibilidade de se enfrentar os gravíssimos problemas como o analfabetismo, o acesso e a permanência nas escolas do Campo e a estrutura e financiamento dessas escolas, que afligem a Pátria que se quer Educadora.

Arroyo (2010, p.10) sintetiza bem essa ideia ao dizer que as “ $[\ldots .$.$] imagens tão negativas$ 
Revista Educação e Políticas em Debate - v. 7, n. 1, p. 152- 169 - jan./abr. 2018 - ISSN 2238-8346 do campo e de suas escolas tiveram e têm uma intencionalidade política perversa: reduzir o campo, suas formas de existência e de produção de seus povos à inexistência”. Isso se dá, pois "uma escola no campo representa o centro irradiador das comunidades. Ali, ao seu redor, é o que tudo acontece" (PERIPOLLI; ZÓIA, 2011, p.196). Sem escolas nas comunidades, abre-se margem para uma possível desestruturação cultural e social. Sob esse ponto de vista é que as comunidades camponesas têm apresentado forte resistência ao fechamento de mais escolas. Aliados às articulações por uma Educação do Campo, os movimentos sociais mostram o seu protagonismo na luta pela abertura e adequação de escolas, colocando em prática o que prescreve a Constituição Federal (BRASIL, 1988) e a Lei de Diretrizes e Bases da Educação (BRASIL, 1996) sobre o direito da população do Campo à educação de qualidade, no lugar onde vivem (FERREIRA; BRANDÃO, 2012).

A próxima seção traz as percepções dos sujeitos da pesquisa, bem como estratégia para compreender as possibilidades de transgressão das concepções negativas.

\section{Reflexões sobre as possibilidades educativas da escola multisseriada do campo: trajetórias docentes e discentes}

A apresentação dos olhares dos sujeitos que tecem a história das escolas multisseriadas - professoras e estudantes -, realizando análises a partir do tripé sujeitos-pesquisadorreferencial, tem propósito de evidenciar as práticas que reconhecem e valorizam o potencial formativo do trabalho com a diversidade e a função social dessas escolas nas comunidades.

De acordo com a acadêmica Altair (56 anos, casada, graduada em Geografia e egressa de Escolas Multisseriadas do Campo), o trabalho pedagógico em Escolas Multisseriadas confunde o estudante e dificulta o trabalho do professor.

A professora Rosely corrobora com a colocação de Altair ao afirmar que "não éfácil você estar numa mesma sala apenas com o quadro dividido. Você atende a cinco turmas". Observa-se que, no momento em que a seriação se materializa em uma turma multisseriada, dificulta-se o trabalho do professor, e os estudantes também se sentem prejudicados. A esse respeito, Hage (2014) salienta que a fragmentação do trabalho docente, baseando-se na lógica do modelo seriado urbano, é o que impossibilita o educador de enxergar a turma como um "único coletivo”. Por sua vez, este não consegue realizar o diálogo necessário entre os diferentes níveis e idades.

Contudo, a professora Rosely, hoje diretora de Escolas do Campo, descreve uma das 
Revista Educação e Políticas em Debate - v. 7, n. 1, p. 152- 169 - jan./abr. 2018 - ISSN 2238-8346 estratégias encontradas por ela na tentativa de amenizar essa dificuldade e atender a todos os estudantes, quando trabalhava em turmas multisséries: “[...] a gente se virava nos trinta. Eu trabalhava o mesmo assunto, [...] aí eu conseguia diferenciar e puxar mais na hora das atividades. Eu penso que por isso o grande êxito dos alunos naquela época aprenderem mais. Porque você trabalhava junto”. Essa fala revela que, quando se deixa de lado a visão de união de várias séries num mesmo tempo e espaço e se "trabalha junto", utiliza-se a diversidade a favor do processo educativo.

Arroyo (2010) alinha-se a este pensamento e completa dizendo que esse tipo de enturmação possibilita organizar o trabalho em sala de aula por grupos, ciclos ou fases de formação que, por sua vez, permite ao professor socializar, trabalhando o tempo, o espaço, a produção, os rituais, os valores, a cultura, sendo esta a verdadeira função da escola e não somente saber ler e escrever. Desse modo, os convívios respeitando os tempos humanos “[ [...] vai além da lógica seriada ou multisseriada. É a lógica do viver, do aprender humano, do socializar-nos como sujeitos culturais, intelectuais, éticos, sociais, políticos, identitários" (ARROYO, 2010, p. 19).

Outro aspecto importante sobre a experiência educacional em escolas multisseriadas é apresentado pelo acadêmico João, egresso de escola multisseriada, ao enfatizar a maneira como a relação social dentro e fora da escola está acentuada em sua na memória. Ele afirma: “eu confesso pra você que eu recordo mais é a questão da socialização, da convivência com os colegas. Era tranquilo, não havia nenhuma desavença. Até porque as famílias eram bem próximas ali. Eram amigas, companheiras, havia respeito".

$\mathrm{Na}$ cultura camponesa, as relações sociais são repletas de valores humanos fundamentais. Esses valores “[ [...] se concretizam em múltiplas práticas de ajuda mútua entre vizinhos. [...]. Essa tradição cultural leva-os a praticarem vários trabalhos coletivos para o bem da comunidade [...]” (TARDIN, 2012, p. 184). Ainda nessa perspectiva, a professora Rosely relata a maneira como conduzia as atividades em grupo, levando em consideração esta característica da cultura camponesa: "[...] tinha muito daquilo: olha, você é o líder desse grupo. Pegava os mais espertos. Fulanim não terminou, vamos ajudar ele? Vamos propiciar a ele esse momento de fazer a atividade junto com a gente?”. Essa fala nos remete a discussão feita por Weigel e Lira (2010), na qual elas afirmam que, dessa maneira, o estudante aprende, juntamente com os colegas de diferentes faixas etárias e graus de profundidade, conteúdos significativos para o seu modo de vida, tal como ocorre na vida real, na qual, em situações de problema a criança, menos experiente, procura o auxílio do outro, mais experiente. 
Outro ponto de extrema relevância é a possibilidade de se extrapolar os limites da sala de aula. Sobre isso, destaca-se o seguinte relato da acadêmica Altair, no qual ela narra as atividades realizadas por sua professora:

\begin{abstract}
lembro que a gente estudava debaixo de um pé de laranja, um pé de mutamba. A gente ficava lá de baixo. Não tinha horário, a gente olhava o sol que ia passando. Aí quando o sol ia rodando a gente ia mudando de lugar. A gente sentava mesmo em cima de uns tocos lá. A aula acontecia ali. E eu tenho muitas lembranças boas dessas aulas. Eu lembro que o lanche era laranja. Ai ela ficava o tempo todinho descascando laranja pra nós. […] Mala. Cavalo. Boi. Ela mostrava mesmo. Burro. Lá mesmo você conseguia ver. Ela mostrava: "tá vendo lá? É um cavalo". E com isso ela ia trabalhando. O que era um cavalo, o que era um boi. Ai ela ia falando: "isso aqui começa com C". Pelo que eu lembro eu acredito que a gente aprendia.
\end{abstract}

A fala da acadêmica destaca a concepção de que a educação não se dá num único lugar, nem tão pouco se restringe a um único modo de organização. A criança aprende em casa, com a família, com os adultos em diferentes espaços, com outras crianças em momentos de interação, "debaixo de um pé de mutamba", vendo o sol rodar, observando tudo o que está ao redor.

No que se refere ao contexto em que se dá a educação nas Escolas do Campo, a professora Guiomar apresenta um depoimento a respeito da forma como tomou conhecimento das situações adversas que permeavam o cotidiano dos estudantes. Visivelmente comovida, ela narra que, a princípio, era uma professora extremamente rígida que não priorizava as necessidades específicas da sua turma e que não compreendia o motivo pelo qual as crianças chegavam à escola sujas e sem realizar as tarefas. Até que, num certo período do ano, a frequência nas aulas diminuiu e a sala ficou vazia. Ela conta:

por se tratar de uma escola de carvoeira, teve um período que eles sumiram da escola. Quando eu entrei numa carvoeira, foi a primeira vez, eu levei o maior susto. Era um cenário muito feio. Muita fumaça. Eles moravam em casa de lona, de plástico, aquele plástico preto. Dormiam numa cama feita de vara pra colocar o colchão por cima. A água que eles usavam para tomar banho era uma água que por cima tinha uma nata preta. E eram crianças muito pequenas. Eu lembro que o menino mais velho que eu tinha na sala era um rapazinho de doze anos. Ai eu chamei os pais e falei: "mas eles não estão indo pra aula. Vou levar vocês pro promotor". Ai uma dona falou comigo assim: "Não faz isso minha filha. Nós tava atrasado com nossa produção. Se a gente não produzir o que o moço quer que a gente produza, eles vão mandar a gente embora. E a gente não tem pra onde ir". Eu era muito nova. Eu tinha dezoito anos. Eu fiquei muito assustada com aquilo ali. Eu lembro que eles me explicaram que precisavam da ajuda das crianças para trabalhar, para ensacar o carvão, ajudar a arrastar. Arrastar. Porque eles não davam conta de carregar até o caminhão. Eles andavam quase $6 \mathrm{~km}$ arrastando o saco de carvão. 
Revista Educação e Políticas em Debate - v. 7, n. 1, p. 152- 169 - jan./abr. 2018 - ISSN 2238-8346

A questão do trabalho no Campo carrega em si características conflitantes. É verdade que a "lida diária” está completamente interligada ao "ser camponês", entretanto, quando deixa de ser um meio pelo qual o sujeito recolhe e/ou transforma a natureza “[ [...] para assegurar a satisfação das necessidades vitais e a reprodução social” (TARDIN, 2012, p. 183), e passa a ser um instrumento para a expansão do capital, no qual "se a gente não produzir o que o moço quer que a gente produza eles vão mandar a gente embora", este trabalho torna-se um meio de exploração, perdendo o seu traço humano, formativo e cultural.

Dando prosseguimento ao seu relato, a professora Guiomar conta, tendo sua fala embargada pelas lágrimas, que, a partir desse momento, pôde compreender a imprescindibilidade de se ter um olhar sensível para a realidade da criança, do estudante do Campo. Percebe-se que houve uma grande transformação na sua prática, bem como na sua formação pessoal e profissional. Todavia, é preciso reiterar que, a priori, não se trata de uma tarefa fácil. Nesse ponto, ergue-se a necessidade de uma formação adequada para o professor do campo, que vai além da formação inicial.

$\mathrm{O}$ acadêmico João traz a questão sobre a formação dos educadores e a elege como principal fator dificultador da aprendizagem. Entretanto, quando dá continuidade ao relato, ele faz um contraponto à sua própria fala: “mas, como falei anteriormente, a escola do Campo, lá no interior, foi onde eu aprendi a ler e a escrever, a outra deu prosseguimento àquele conhecimento que eu já tinha”. Por meio desse depoimento, percebe-se que, embora seja um fator importante, não é o único indicador que tem relevância sobre a aprendizagem. Esse aspecto é confirmado também pela acadêmica Altair que, apesar de sua primeira professora apresentar um baixo nível de escolaridade, reconhece que houve aprendizagem.

De fato, um dos maiores percalços para o exercício da docência em escolas multisseriadas do Campo é a falta de uma formação inicial específica para se trabalhar nessa realidade, onde, além da heterogeneidade em sala de aula, o professor tem que lidar com a sobrecarga de trabalho. Nesse ponto, a professora Rosely relata:

a minha experiência foi muito bacana, mas, porém, muito sofrida. Porque quando eu comecei em 1980, eu ainda não tinha uma formação acadêmica. Eu simplesmente tinha o Ensino Fundamental, que era necessário naquela época. E iniciei numa turma de trinta e três alunos em cada horário, então eu tinha sessenta e seis alunos. Sozinha. Eu mesma era professora, era merendeira, eu era tudo ali na comunidade.

Por outro lado, Guiomar, ex-professora de turma multisseriada, expressa o seu encanto pela Educação do Campo, atual disciplina do curso de Pedagogia, e salienta que esta deveria vir desde o início do curso, uma vez que “nós, que tivemos essa experiência de ser professor no meio 
Revista Educação e Políticas em Debate - v. 7, n. 1, p. 152- 169 - jan./abr. 2018 - ISSN 2238-8346 rural, sabemos que não é com um ou dois semestres que você vai conseguir fazer com que o curso de Pedagogia entenda o que é uma Educação do Campo, o que é essa criança do Campo”.

Embora seja essencial uma formação docente específica, não pode ser ignorada a criatividade do educador que, na prática diária, aprende a aprender e aprende a ensinar. Isso pode ser claramente percebido na fala da professora Guiomar: "a partir do momento que eu vi a realidade daquelas crianças eu comecei a estudar, a pesquisar. Eu comecei a perguntar. No meu último ano de trabalho lá, eu já posso dizer que eu era outra professora. Mas eu tive uma busca intuitiva.”. E continua: "eu não me formei para ser professora. Eu me transformei professora. Só que eu me apaixonei pela profissão. Aí fui buscando aprender".

$\mathrm{Na}$ contramão das inúmeras possibilidades sociais e didático-pedagógicas produzidas nas escolas multisseriadas, conforme apontado, tentativas governamentais de erradicação dessas escolas têm ganhado espaço. Quando questionados a esse respeito, os sujeitos participantes dessa pesquisa manifestaram diferentes perspectivas, que desenham bem o panorama do fechamento de escolas do Campo. A professora Rosely defende:

"para as escolas, é natural, não porque estou aqui na direção, mas, realmente, porque
está ficando complicado. Não tá tendo menino. Não tem menino. O meio rural sempre
foi muito pequeno. Pra você ver, essa escola que eu iniciei, em 1980 , eu tinha sessenta
e sete alunos, trinta e três de manhã e trinta e quatro à tarde. Hoje, a escola da
comunidade mesmo tem quatro alunos. E não é porque os pais não levam os alunos
pra escola não. É porque realmente não tem aluno. [É] o êxodo rural. Hoje vocêe
chega nas comunidades e não vê mais jovens. Você não tem mais água. Você não tem
como plantar. A seca está demais. Como que uma família jovem vai sobreviver no
meio rural sem emprego, sem nada. Só ficam os velhos aposentados".

A acadêmica Altair completa:

"eu achei melhor porque os alunos vão de ônibus. Mas tem a questão de muito perigo,
de passar o tempo inteiro dentro do ônibus. Inclusive, eu já acompanhei alunos que
ficam passando mal por causa do ônibus quebrar no meio do caminho e demorar
chegar em casa. Como eu vivi em frente a uma escola, eu via muito isso. Imagine os
pais lá esperando os filhos. Nesse ponto eu acho que foi mais difícil".

Conforme já assinalado, há por trás da política de fechamento de escolas do Campo uma política de desmonte do Campo, aliada à política do transporte escolar e de expansão do agronegócio. Utilizam-se concepções negativas que supervalorizam os limites e desafios enfrentados nessas escolas, perpetuando o estigma de educação precarizada, bem como do discurso da economia financeira, criando-se um debate superficial e escolarizado que busca ocultar o verdadeiro objetivo com o fechamento dessas escolas. O acadêmico João reafirma 
Revista Educação e Políticas em Debate - v. 7, n. 1, p. 152- 169 - jan./abr. 2018 - ISSN 2238-8346 esse posicionamento ao enfatizar:

\begin{abstract}
"a impressão que passa é que o ensino não é levado a sério. Mas o fechamento de escolas tem outras coisas por trás disso, interesses financeiros dos donos de ônibus para transportar essas crianças para uma cidade maior. Eles preferem levar esses dez alunos para outra comunidade ou pra cidade, para estudarem lá e simplesmente fecham aquela escola como se aquilo não tivesse nenhum valor sentimental para aquelas pessoas que moram lá e que estudaram lá naquela comunidade. Eu vejo isso com muita tristeza. Mas isso reflete muito bem como é movida a educação no Brasil. Como nossos representantes pensam a educação pública nesse país”.
\end{abstract}

Este depoimento mostra que, ao se fechar uma escola, dá-se a entender que a sua função social na comunidade, assim como a cultura e história local, não são levados em consideração. Quanto a isso, a professora Guiomar relata: "eu vejo o quanto é prejudicial essa criança sair do campo para vir estudar na cidade. É muito ruim pra ela”. Em seu depoimento, ela coloca em questão, também, outras consequências do transporte dos estudantes do Campo em direção à cidade: a diminuição no aproveitamento escolar devido aos problemas com o transporte, a perda das identidades culturais e o distanciamento do convívio familiar, complicando a relação entre família e escola.

Quando os sujeitos da pesquisa foram levados a rememorar os tempos e espaços que marcaram esta experiência, evocou-se um mosaico de representações e sentimentos que nos possibilitam compreender a importância cultural, social e histórica das escolas multisseriadas do Campo. A acadêmica Altair afirma: "foi ali que eu comecei a entender o que eu sou hoje. Na minha região tinha muito analfabeto. Não era nem pra eu ter estudado. E ela foi uma base na minha vida”. $\mathrm{O}$ acadêmico João também demonstra o importante papel dessa escola em sua história dizendo: "eu falo sempre que foi ali onde eu comecei. Se hoje eu estou na universidade, tem um pouquinho dali. Ali foi onde eu dei os primeiros passos. Foi naquela escola”.

As professoras confirmam essa importância e reforçam o peso da experiência docente nessas escolas, na edificação da sua história pessoal, como um lugar de valores humanos, cultura rica e luta pelos direitos que lhe são recusados. A professora Guiomar expressa: “ $a$ representação que eu tenho é de uma escola totalmente valorizada pela comunidade e pelos alunos. Para mim é o que ficou de mais forte. Significou um começo que eu carrego para toda a minha vida. Uma grande lição de vida que foi capaz de me transformar como ser humano”.

Rosely, também professora, completa afirmando:

"é uma lição de vida. Um aprendizado muito grande. A gente aprende muito a dar valor à vida. Porque uma coisa é ser professora aqui na sede, com o que hoje a gente fala "um mínimo de conforto". Mas, pra uma turma multisseriada do meio rural é 
Revista Educação e Políticas em Debate - v. 7, n. 1, p. 152- 169 - jan./abr. 2018 - ISSN 2238-8346

ter tudo aqui na sede e lá não ter nada. O interessante que eu acho é vocês estarem buscando conhecer o outro lado da moeda. Eu sou encantada. Eu aprendi a gostar".

A escola multisseriada permitiu o acesso à escolarização inicial a uma parcela considerável de brasileiros, bem como foi a primeira oportunidade de emprego de outro número significativo de profissionais da educação, em especial, os participantes desta pesquisa. Nesse sentido, a escola representa muito mais do que um espaço físico onde ocorre a alfabetização, coloca-se no espaço do direito, direito ao saber, ao conhecimento, à cultura.

\section{A História das escolas multisseriadas do Campo: apontamentos finais}

A partir das memórias e do percurso histórico realizado nesta pesquisa, é possível inferir que o modelo de organização escolar multisseriado carrega sobre si representações negativas suscitadas por fatores históricos, sociais e, principalmente, políticos. Essas representações negativas foram incorporadas pela sociedade e serviram, e ainda servem, de justificativa e incentivo para a expansão de políticas de fechamento de escolas do Campo.

Todavia, percebemos que, quando se fecha uma escola multisseriada do Campo, há o descredenciamento da cultura e história local, da mesma maneira que se fere o direito à escolarização dos povos do Campo no lugar em que vivem e convivem, ocasionando devastação das identidades culturais. Além disso, deslegitimam a sua história como escola forjada diante da possibilidade de acessar aos sujeitos camponeses a educação escolar, independentemente de sua idade, grau de aprendizagem ou mesmo diante das inóspitas condições pedagógicas e físicas do espaço educativo.

Após as análises e discussões das informações levantadas na pesquisa de campo, constatamos que, mesmo diante das barreiras enfrentadas nas escolas multisseriadas, existem possibilidades que, tendo como cerne a valorização da diversidade, possibilitam ao professor realizar um trabalho significativo e contextualizado, que atenda às demandas educacionais. Daí que foram evidenciadas estratégias pedagógicas bem sucedidas, como: o trabalho com o mesmo conteúdo, havendo a diferenciação nos níveis de dificuldade das atividades; a organização por grupos de idades próximas, valorizando o princípio dos tempos humanos de aprendizagem bem como a cooperação entre os estudantes; e atividades fora dos limites da sala de aula, utilizando a natureza ali presente como recurso pedagógico.

Apreendemos que essa escola multisseriada do Campo constitui-se como uma base para a formação humana, na mediada em que não se baseia na fragmentação ou na seletividade 
Revista Educação e Políticas em Debate - v. 7, n. 1, p. 152- 169 - jan./abr. 2018 - ISSN 2238-8346

própria da seriação. Ela se fundamenta nos convívios humanos que a diversidade proporciona, ressaltando a diversidade - de sujeitos, de crenças, de saberes, de modos de lidar com a natureza - como a essência da cultura camponesa, constituindo a sala de aula como espaço rico de aprendizagem, convivência, solidariedade e respeito.

Constata-se que, apesar das profundas mazelas que dificultam a realidade dessas escolas, elas possuem um papel fundamental na História da Educação no Brasil, assim como na construção das próprias identidades dos sujeitos. Para os professores e estudantes, essa escola significa muito mais do que um espaço para aprender a ler e a escrever; ela traduz-se em direito, e na medida em se situa na perspectiva do direito, exprime a sua função social nas comunidades nas quais estão inseridas. E é nesse sentido que se traduz a sua importância social, política e cultural.

É pelo reconhecimento dessa importância histórica das escolas multisseriadas do Campo, e pela mobilização social camponesa, que o Programa Escola da Terra ergue-se como política pública para o atendimento a essa especificidade central da Educação do Campo, nos anos iniciais do Ensino Fundamental.

Ainda há muito a ser desvelado acerca das escolas multisseriadas do Campo e sobre a sua importância para a História da Educação Brasileira como modelo de escola camponesa que garantiu, e ainda garante, a camponesas e camponeses, o acesso à educação escolar em sua diversidade subjetiva nos extensos espaços rurais brasileiros. Aqui trouxemos alguns apontamentos que, em si, suscitam a necessidade de mais pesquisas, o que confere a este estudo uma significativa relevância na desconstrução do estigma construído sobre o fracasso das escolas multisseriadas do Campo e a necessidade de sua "superação", inclusive no espaço da própria academia.

\section{Referências}

ANTUNES-ROCHA, Maria I.; HAGE, Salomão M. (Org.). Escola de direito: reinventando a escola multisseriada. Belo Horizonte: Autêntica, 2010.

ARROYO, Miguel G. Prefácio: Escola de direito. In: ANTUNES-ROCHA, Maria I.; HAGE, Salomão M. (Org.). Escola de direito: reinventando a escola multisseriada. Belo Horizonte: Autêntica, 2010. p. 9-14.

FERREIRA, Fabiano J.; BRANDÃO, Elias C. Educação e politicas de fechamento de escolas do Campo. VIII Seminário do trabalho: trabalho, educação e políticas sociais no século XXI. Unesp, 2012. Disponível em: <www.estudosdotrabalho.org/texto/gt1/educacao_e_politica.pdf>. Acesso em: mai. 2017. 
Revista Educação e Políticas em Debate - v. 7, n. 1, p. 152- 169 - jan./abr. 2018 - ISSN 2238-8346

FERRI, Cássia. Classes multisseriadas: que espaço escolar é esse? Florianópolis: UFSC, 1994.

FONSECA, Fabrício A. Nucleação de escolas na região do Canto do Engenho: impactos culturais e educacionais. Montes Claros: Unimontes, 2011.

GIL, Antônio C. Como elaborar projetos de pesquisa. 3. ed. São Paulo: Atlas, 1991.

GONÇALVES Gustavo B. B; ANTUNES-ROCHA, Maria I.; RIBEIRO Valdiner. Programa Escola Ativa: um pacote educacional ou uma possibilidade para a escola do Campo? In: ANTUNES-ROCHA, Maria I.; HAGE, Salomão M. (Org.). Escola de direito: reinventando a escola multisseriada. Belo Horizonte: Autêntica, 2010. Cap. 3, p. 49-60.

HAGE, Salomão A. M. A Multissérie em pauta: para transgredir o Paradigma Seriado nas Escolas do Campo. 2008. Disponível em: $<$ www.faced.ufba.br/sites/faced.ufba.br/files/multisserie_pauta_salomao_hage.pdf $>$. Acesso em: abr. 2017.

Transgressão do paradigma da (multi)seriação como referência para a construção da escola pública do Campo. Revista Educação e Sociedade, Campinas, v. 35, n. 129, p. 1165-1182, 2014. Disponível em: <www.scielo.br/pdf/es/v35n129/0101-7330-es-35-129-01165.pdf>. Acesso em: abr. 2017.

JUSTINO, Érica F. Escola da terra: um estudo sobre os desafios e possibilidades na formação de professores em Classes Multisseriadas. III Seminário Nacional de Estudos e Pesquisas sobre Educação no Campo - V Jornada de Educação Especial no Campo - XIII Jornada do HISTEDBR. 2015. Disponível em: < www.semgepec.ufscar.br>. Acesso em: jun. 2017.

MAZUR, Ivania P. Fechamento de escolas do campo: alguns apontamentos. V Seminário Nacional Interdisciplinar Em Experiências Educativas. Unioeste, 2015. Disponível em: <cacphp.unioeste.br/eventos/senieeseminario/anais/Eixo3/FECHAMENTO_DE_ESCOLAS_ DO_CAMPO_ALGUNS_APONTAMENTOS.pdf>. Acesso em: set. 2016.

MOREIRA, Herivelto; CALEFFE, Luiz G. Metodologia da pesquisa para o professor pesquisador. Rio de Janeiro: DP\&A, 2006.

NEVES, Maria de Fátima. O Método de Lancaster e a memória de Martim Francisco. REUNIÃO ANUAL DA ASSOCIAÇÃO NACIONAL DE PÓS-GRADUAÇÃO E PESQUISA EM EDUCAÇÃO (ANPED). Caxambu, 2000. Disponível em: <www.anped.org.br/reunioes/23/textos/02 10t.pdf>. Acesso em: jul. 2017.

PERIPOLLI, Odimar J.; ZÓIA, Alceu. O fechamento de escolas do campo: o anúncio do fim das comunidades rurais camponesas. Revista Educação, Cultura e Sociedade. Sinop/MT, v.1, n.2, p.188-202, 2011.

RAMAlHO, Maria N. M. Na Roça, Na Raça... Eu Me Tornei Professor: um estudo sobre a formação docente de professores de classes multisseriadas no Norte de Minas Gerais e Vale do Jequitinhonha. Piracicaba: UMP, 2008. Disponível em: < www.unimep.br/phpg/bibdig > . Acesso em: out. 2016. 
RODRIGUES, Caroline Leite. Educação no Meio Rural: Um estudo sobre salas multisseriadas. Belo Horizonte: UFMG, 2009. p. 209. Disponível em: < www.bibliotecadigital.ufmg.br/.../educa_o_no_meio_rural>. Acesso em: out. 2016.

SANTOS, Fábio J. S.; MOURA; Terciana V. Políticas educacionais, modernização pedagógica e racionalização do trabalho docente: problematizando as representações negativas sobre as classes multisseriadas. In: ANTUNES-ROCHA, Maria I.; HAGE, Salomão M. (Org.). Escola de direito: reinventando a escola multisseriada. Belo Horizonte: Autêntica, 2010. Cap. 2, p. 3547 .

TAFFAREL, C. Z.; MUNARIM, A. Pátria educadora e fechamento de escolas do campo: o crime continua. Revista Pedagógica, Chapecó, v. 17, n. 35, p. 41-51, 2015.

TARDIN, José M. Cultura Camponesa. In: CALDART, Roseli Salete (Org.). Dicionário de Educação do Campo. Rio de Janeiro, São Paulo: Expressão Popular, 2012. p. 181-188.

VENDRAMINI, Célia R. Qual o futuro das escolas no campo? Educação em Revista, Belo Horizonte, v. 31, n. 03, p. 49-69, 2015. Disponível em: <www.scielo.br/scielo>. Acesso em: jan. 2017.

WEIGEL, Valéria A. C. M.; LIRA, Márcia J. O. Escolas Sataré-Mawé do Marau-Urupadi: limites e possibilidades da multissérie na educação escolar indígena. In: ANTUNES-ROCHA, Maria I.; HAGE, Salomão M. (Org.). Escola de direito: reinventando a escola multisseriada. Belo Horizonte: Autêntica, 2010. Cap. 23, p. 377-387. 